\title{
Article Title
}

Turnover and balance between exploration and exploitation processes for high-performance teams

\begin{abstract}
Purpose: This paper uses macro-level theories based on the equilibrium between the exploration and exploitation of resources in an organisation to examine the association between turnover and performance through the analysis of a professional football (soccer) team in the Premier League, namely Manchester United Football Club.

Design/methodology/approach: This study compiles historical data for 24 seasons of the Premier League between 1984-1985 and 2008-2009. Using these data, we define measures of performance and player turnover.

Findings: The results show the existence of an inverted U-shaped relationship between exploration and exploitation (turnover processes) and group efficiency under certain conditions, such as the number of work systems considered and the period during which the level of turnover is calculated.
\end{abstract}

Originality/value: Most research on employee turnover suggests that reductions in turnover have a positive effect on the efficiency of the organisation. However, the present study suggests that worker turnover can be analysed using theories based on the equilibrium between the processes of resource exploitation and exploration, especially for high-performance work groups. These theories predict an inverted U-shaped relationship between turnover and performance, which has been identified through empirical analysis. Keywords: exploration, exploitation, rotation, efficiency, sport, employee turnover 


\section{Introduction}

Employee turnover has received substantial attention in the academic and professional sectors because of the serious consequences it has on the efficiency of organisations (Ton and Huckman, 2008). Most research on employee turnover has focused on identifying its determinants and analysing its causes in order to regulate (reduce) turnover levels within organisations in a conscious manner. Such reductions would allow for more precise control of organisational efficiency. However, the study of the consequences of labour turnover has received less attention from researchers (e.g. Mobley, 1982; Glebbeek and Bax, 2004; Ton and Huckman, 2008; and Stanley and Zubanov, 2009). This oversight is a result of the belief that the main (or indeed, the only) consequence of labour turnover is organisational efficiency.

The use of the terms "exploitation" and "exploration" (March, 1991) has become widespread and is now a key element of the analysis of organisational survival, competitive advantage, organisational learning, technological innovation and organisational design. Most research on employee turnover suggests that reductions in turnover have a positive effect on the efficiency of the organisation. However, the present study suggests that worker turnover can be analysed using theories that consider the equilibrium between the processes of resource exploitation and exploration, especially in the case of highperformance work groups.

A review of literature on exploration and exploitation processes shows that research conducted at the micro level, i.e. at the level of the individual or group, is relatively rare. 
Most research on the exploration and production processes occurs at the macro level, i.e. at the organisational, inter-organisational or national level. In addition, Gupta, Smith, and Shalley (2006) warn that the results of research on exploration and exploitation processes at the macro level cannot be generalised to micro situations, because the contexts involved are too different. Thus, research on the processes of exploitation and exploration, including their definitions, continuity, orthogonality, ambidextrousness, points of balance, duality and specialisation, should be performed separately.

Our main goal is to determine whether it is possible to transfer the process-based theories of exploration and exploitation to small, high-performance workgroups by studying the relationship between team member turnover and team efficiency on high-performance sport teams. More specifically, our study attempts to verify the existence of an inverted U-shaped relationship between the performance of the group in the medium-to-long term and the level of turnover. Since labour turnover can enhance organisational exploration, the existence of such relationship would contribute evidence of the existence of an optimal equilibrium between exploration and exploitation, assuming that both processes are the two extremes on the same continuum. To achieve this objective, we collected historical data from 24 seasons for one of the most prestigious football leagues in the world: the Premier League, and, more specifically, for one of the most popular teams in the world (with more than 659 million fans around the world): Manchester United Football Club. The selection of this football team has several pros and cons. On the one hand, the study of just one case offers more control over the outcome and the variables involved and makes it possible to identify "unobservables" that may affect the conclusions. In particular, the fact that for the entire time horizon considered, Manchester United has had the same manager makes it 
possible to control for a key variable that can significantly affect team performance (see Ter Weel [2011] and Nissen [2014]; see also Dohm and Lopez [2015] for American football). On the other hand, a certain degree of caution needs to be taken in the statistical extrapolation of the results. This being said, it is possible to carry out an analytical extrapolation that can potentially provide insight into the efficiency of sport teams. Unlike previous research, we suggest a new perspective in research on turnover, adding new elements in the field of sport: the period of time and the segmentation of the work systems. Moreover, this research followed a deductive approach, which led us to propose an inverted U-shaped relationship between turnover and performance. Conversely, the parameterisation of turnover, based on the period of time and the segmentation of the work systems, was carried out according to an explorative approach, considering data from 40 different cases.

\section{Review of the Literature}

The relationship between employee turnover and organisational performance has been discussed from a variety of perspectives, with mixed results (Siebert and Zubanov, 2009). Based on a study of the costs and benefits of an organisation, Dess and Shaw (2001) showed that employee turnover in large organisations produces a decrease in organisational efficiency, as the rotation of workers erodes the human capital of a company. In the same vein, Shaw, Gupta and Delery (2005) and Shaw, Duffy, Johnson and Lockhart (2005) identified a negative relationship between employee turnover and organisational efficiency. On the contrary, Ableson and Baysinger (1984) proposed that turnover has beneficial results, because it allows for the replacement of lower-efficiency workers with better ones. The idea that employee turnover can be either positive or negative is reflected in comments 
made by several multinational organisations that have publicly voiced their interest in achieving a turnover ratio of 10-12 percent to maintain a high level of organisational efficiency (Economist, 2007: 74).

According to Dess and Shaw (2001), there are no studies at the organisational level that reflect a non-linear, inverted U-shaped relationship between employee turnover and efficiency. However, the work of Glebbeek and Bax (2004) identified this relationship, although their study failed to confirm it statistically. Later, Harris, Tang and Tseng (2006) found a curvilinear relationship at an aggregate level in various Australian companies, and Siebert and Zubanov (2009) were able to validate this finding statistically in a large retail company in the UK. However, as Gupta, Smith and Shalley (2006) suggest, these results cannot be extrapolated to individuals or to groups, such as work teams.

\section{Work Teams}

Teams can be defined either as groups of individuals who work together to produce goods or provide services for which they are mutually accountable (Mohrman, Cohen and Mohrman, 1995) or as individuals who are brought together by a common goal or task (Katzenbach and Smith, 1999). Learning (e.g. Dechant, Marsick and Kasl, 2000) and efficiency (e.g. Edmonson, 1999) have been widely studied in work teams, but conclusions regarding the proper management of the balance between exploitation and exploration remain elusive (Lunnan and Barth, 2003). Recent research in this area, including studies by Ton and Huckman (2008), has provided guidelines for further research that have been incorporated in this study. 
The distinction between increasing efficiency by means of maintaining a small group of workers that does not change over time and seeking new ideas with the hiring of new workers is an example of the organisational processes of resource exploitation and exploration, respectively (March, 1991). Correspondingly, each rate of employee turnover can be seen as a particular equilibrium between exploitation and exploration. This could explain the fact that employee turnover on teams can be seen as a tool with both positive and negative effects on group outcomes. This potential duality of working group efficiency may be the reason for the inverted U-shaped relationship between such efficiency and the signings and trades that we see at the macro level.

\section{Work Systems}

Bamberger and Meshoulam (2000) suggested that organisations and, by extension, work groups can have multiple work systems. Two archetypal systems are the commitment system and the secondary system, also known as the control or support system. On the one hand, workers who are included in the commitment system contribute some specific advantages to the organisation and are able to work in a more turbulent environment. On the other hand, workers who are part of the secondary system complement the contributions of other system workers, engage in more routine processes and cost less. This differentiation is often observed in the selection process, as the costs involved in hiring workers in the commitment system have a great impact on the organisation and are considerably greater than those associated with hiring workers for the secondary system. On this basis, Lepak and Snell (1999) have proposed that it is a mistake to have a single human resource hierarchy that is intended to optimise the efficiency of all employees of an organisation, arguing that organisations need to apply different human resource standards 
according to the system (central or commitment and support or secondary). It has also been suggested that there might be a need for intermediate systems that are positioned between these two extremes.

In the field of sport, there are several studies that have considered the work system, either directly or indirectly, in the analysis of the team performance. Trequattrini, Lombardi, and Battista (2015) suggest a list of players’ attitudes on football teams, in order to classify them and assess the relationship among them by means of network analysis. From a different perspective, Clopton (2011) analysed the contribution of social capital through the perspective of a resource-based view of athletes. To achieve this goal, this study identifies the different roles of athletes and the importance of each in order to evaluate their effects on performance. The role and the importance of the players on their teams in Major League Baseball and the National Hockey League were two elements in the study of the team performance conducted by Foster and Washington (2009). Their results show, directly or indirectly, that the work system is a core element in research on team performance. From a different perspective, Wells and Peachey (2011) suggest that some roles affect turnover and the team performance, and more specifically, that the type of leadership is a key element in the analysis of these behaviours and outcomes.

\section{Benefits and costs of exploration and exploitation processes in work teams}

At this point, it is necessary to determine the costs and benefits that should be considered in the evaluation of work group member turnover based on the relevant macro-level research. Zubanov and Siebert (2009) have identified two major types of benefits from turnover. The first type of benefit is the improvement and revitalisation of the workforce that occurs by 
eliminating the worst group of workers. This type of turnover is often considered "involuntary", and includes layoffs. Although it is difficult to quantify the efficiency of a worker in a group at the time of his or her hiring, the turnover of group members who are part of the central system (the core) will have a greater impact, so it is expected that turnover among these group members will be lower than in the other systems. On the other hand, the cost of the mistakes that occur in the hiring of secondary workers is generally lower, so a higher level of turnover can occur without the group being significantly affected. Furthermore, in working groups in which pay is variable and depends largely on employee performance, voluntary turnover increases significantly, especially among secondary system workers, who are already paid less and receive fewer group benefits. As indicated by Siebert and Zubanov (2009), these two benefits stop increasing once a certain threshold of member turnover is reached.

Similarly, we can identify two types of costs that are related to employee turnover. The first cost is the loss of specific human capital (Lepak and Snell, 1999), which increases as the level of turnover within a group increases. Such increases are detrimental to the efficiency of the group, because both tacit employee knowledge and formally learned knowledge disappear from the group (Kacmar, Andrews, Van Rooy, Steilberg and Cerrone, 2006). Turnover in a work group implies the hiring of new employees who will have to learn the formal operations involved in their work and assimilate the routines established by the group through training and adaptation. Therefore, it can be expected that the performance of a worker during this process will be much lower than expected, and the corresponding turnover will generate a proportionally higher cost (Cascio, 1998). 
Meanwhile, Morrow and McElroy (2007) note that turnover also reduces the group’s tacit knowledge, e.g. information about how to manage time effectively when working with one's colleagues or how to decode the informal responses that are accepted within the group, but are not formalised. It is expected that the costs associated with employee turnover under the commitment system will be greater than the costs associated with employee turnover in the secondary system. The second type of costs is related to productivity losses due to dysfunction during turnover. Dysfunction during voluntary employee turnover is often linked to pay-for-performance practices (Harrison, Virick and William, 1996) among the best workers, as opposed to worker recruitment practices (Shaw, Delery, Jenkins and Gupta, 1998). Therefore, the costs of labour turnover due to dysfunction are influenced by the movements in the labour market, especially among workers in the commitment system, because the most valuable workers on the market are also the scarcest.

\section{Model and Hypotheses}

The above considerations have prompted us to consider the following research question: Is there a point of equilibrium in the turnover of members of a high-performance group that maximises group efficiency? Based on the results of macro-level research (e.g. Dess and Shaw, 2001; Glebbeek and Bax, 2004; Tang and Tseng, 2006; and Siebert and Zubanov, 2009) on exploration and exploitation, a nonlinear relationship between these two elements is expected. More concretely, the following hypothesis is presented:

H1: There is an inverted U-shaped relationship between the turnover of high-performance (commitment system) group members and efficiency. 


\section{[INSERT FIGURE 1 HERE]}

Team member turnover generates the loss of a portion of group-specific human capital (Lepak and Snell, 1999) and of certain knowledge, skills and abilities that exist on the team (Morrow and McElroy, 2007). Moreover, a decrease in the number of members on a team generally results in the simultaneous addition of new people. Thus, the current team members have two tasks: to unlearn certain routines that they acquired with people who have left the team and to adapt and/or create new routines, according to the characteristics of the new team members. Therefore, we believe that timing is essential, in order to combine turnover with efficiency on teams. On this basis, we present the following hypothesis:

H2: There is an inverted U-shaped relationship between the level of turnover and the efficiency of the work group when a significant amount of time elapses after one or more employees has left.

According to Lepak and Snell (1999), by taking into account only one work system and assuming that all members of a team are similar, certain intractable inefficiencies are generated. Bamberger and Meshoulam (2000) propose the need to segment workers into two work systems; however, there are also several proposals that suggest that segmentation into only two work systems is insufficient. We propose that the more working systems there are, the more accurate the assessed impact of turnover on high-performance teams will be. More specifically, we suggest that there is an inverted U-shaped relationship 
between the level of turnover and efficiency when we consider different levels of importance between the two work systems (control and support systems, or in this case, those players who play the most minutes and the rest of the team), or when we individually consider the importance of each employee (player) based on his status on the team. For this reason, the following hypothesis is proposed:

H3: There is an inverted U-shaped relationship between the level of turnover and the efficiency of the work group when different work systems are weighted.

\section{Methodology}

The most frequent research design adopts either a deductive or an inductive approach throughout the entire process; however, a combination of both approaches has been adopted in this study. We decided to follow a deductive approach to define the relationships between turnover and efficiency of teams according to the reviewed literature, as seen in the statement of hypotheses 1, 2, and 3. However, the parameterisation of the turnover based on the period of time and the segmentation of the work systems followed an inductive approach, with 40 different cases, as seen in the Instruments section.

Two methodological approaches were used to research the relationship between turnover and organisational efficiency from a different perspective. The first approach studies the turnover-efficiency relationship, using a cross-sectional analysis of various organisations (e.g. Arthur, 1994; Guthrie, 2001; and Shaw, Gupta and Delery, 2005); the second approach defends the study of only one organisation, on the grounds that this relationship is 
contingent (e.g. Datta, Guthrie and Wright, 2005; and Lepak, Taylor, Teklead, Marrone and Cohen, 2007).

Using a methodology in which all of the data collected pertain to one organisation, rather than analysing data from several different organisations, offers more control over the outcome and the variables involved in the study (Glebbeek and Bax, 2004). This approach also makes it possible to identify "unobservables" that may affect the relationship between worker turnover and organisational efficiency, which are difficult to identify in a study of multiple organisations. By contrast, the use of a single organisation means that the results are not representative of other organisations. We must accept this disadvantage in order to study the relationship between turnover and organisational efficiency in detail. However, we believe that the main results of this research could still be applied to other similar organisations, especially teams that play the same sport.

Our approach proposes two innovations in the methodology used to study the main subject of this research: turnover on high-performance work teams. The first innovation is that the study conceptualises turnover as a longitudinal construct that encompasses varying time periods rather than employing a cross-sectional design. Likewise, our study also assigns different levels of importance to the years studied, making it possible to model the relationship between turnover and organisational efficiency more precisely. This precision is particularly important with elite sports teams, as reflected in comments made by several trainers and coaches about the time a new player needs to acclimate to the team and learn the team's practices. 
The second innovation is our hypothesis that the level of turnover depends on the role of each of the team members. Although a study of turnover among players on a football team might assume that such a team is a fairly homogeneous group as compared to other types of (non-sports) work teams, the reality is quite different. For this reason, segmenting players into different sub-groups or systems, as proposed by Lepak and Snell (1999), is indeed appropriate. Therefore, a "one-size-fits-all" approach is not used in the research; rather, a large number of subsystems are used to represent and study turnover among the players. At one extreme, we consider the weight of all team members to be the same, whereas at the other, we consider each team member as part of a different subsystem. Between these two extremes, a model with two sub-systems is proposed: the core subsystem, which consists of those players who have played the most games throughout the season (11 players, the number of players that can play at the same time in an official football match), and the secondary subsystem, which consists of the remaining players on the squad (which typically ranges from 11 to 15 players). The possible existence of two subsystems or as many subsystems as there are players on the roster may have important implications for research in this area. Our results should assist managers in making decisions about signing and trading strategies in the short, medium and long term.

\section{The Sample}

To evaluate the hypotheses, the evolution of a work group was analysed for a period of 24 years. More specifically, data were collected from one of the most popular football teams in the world, Manchester United Football Club in the English Premier League. Data were collected for the 24 seasons between 1984-1985 and 2008-2009, mainly from the official website of the Manchester United Football Club. Due to the lack of access to certain 
information, we contacted the club directly, and they provided other information necessary for our research. In conducting the study, the authors considered the season as the unit of analysis, since in the world of football, the performance of a football team is assessed at this level.

The adoption of a research design in which only one team is considered has several limitations in terms of the extrapolation of the results; however, we chose it because one case offers more control over the outcome and the variables involved in the study and makes it possible to identify "unobservables" that may affect the conclusions. Due to the nature of the case, this study focuses on high-achieving teams (according to the scope of the research), so the conclusions cannot suggest implications for the relationship between turnover and efficiency on low achieving teams.

\section{Instruments}

Dependent variable. One of the objectives of this research is to observe the evolution in the performance or efficiency of a team under certain circumstances. Thus, performance is established as the dependent variable in this study. Although there are several ways to evaluate the success or performance of a football team (Espitia-Escuer and Garcia-Cebrian, 2006), we considered the number of points earned during a season to be the best approximation of its efficiency. The number of teams participating in the Premier League has changed throughout its history, so the point values were standardised. We did this by dividing the point values by the number of teams in the English Premier League for that season. In addition, because the number of points earned for wins or draws has also varied throughout history, the points earned in the season (first and second legs) were divided by 
two times the number of points obtained from a win. Thus, a yield equal to 1 would be assigned to a team that won all of its matches in a season, and a return equal to 0 would be assigned to a team that lost all of its matches that season. These considerations are shown in formula (1).

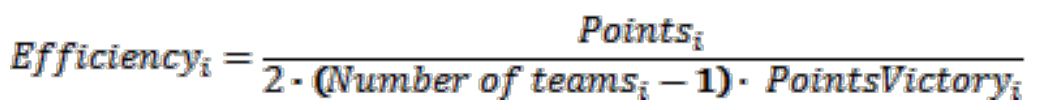

Independent variable. To assess the levels of exploration and exploitation on football teams, we used the degree of turnover or, more specifically, the total number of player signings and trades between seasons. However, there are several ways to calculate turnover: the turnover time (i.e. the number of seasons being considered) and the work system or systems of the football team. Therefore, several alternative means of assessing turnover are proposed. From the perspective of work systems, the importance of the players on a football team is evaluated in four different scenarios:

The first scenario proposes a single work system in which the signing or trading of any player carries the same weight on the team. To evaluate turnover in this scenario, we add the signings $\left(\mathrm{IN}_{\mathrm{i}, \text { all }}\right)$ during the season (i) as well as the trades $\left(\mathrm{OUT}_{\mathrm{i}, \text { all }}\right)$ as compared to those of the previous season (i-1) for all players (all). Because the number of signings and trades on a football team is similar over time, we divided this value by two, in order to more realistically reflect the existing turnover. Finally, noting that the number of players on football teams has changed significantly during the history of the Premier League, we decided to standardise this value by dividing it by the number of players who were on the team (Pi-1) last season (i-1). All of these considerations are shown in formula (2). 


$$
\text { Turnover }_{A, i}=\frac{\left(I N_{i, a l l}+O U T_{i-1, a l l}\right) \cdot \frac{1}{2}}{N_{i-1}}
$$

In the second scenario, we propose a model with two different work systems. The first system consists of the 11 players on the team who have played the most games throughout the season, and the second system is composed of all the other players. In this scenario, to calculate turnover, we only include the signings $\left(\mathrm{IN}_{\mathrm{i}, 11}\right)$ during the season (i), as well as the trades $\left(\mathrm{OUT}_{\mathrm{i}, 11}\right)$, as compared to those of the previous season (i-1) for the 11 players who are part of the first work system; we discarded the signings and trades of the other players on the team. In the same manner as in formula 2, the sum of signings and trades is standardised by dividing the figure by two, and then by the number of players in the work system (in this case, 11). All of these considerations are shown in formula (3).

$$
\text { Turnover }_{B, i}=\frac{\left(I N_{i, 11}+O U T_{i-1,11}\right) \cdot \frac{1}{2}}{11}
$$

The third scenario also employs a model with two work systems, the first made up of the 11 players who have played the most minutes throughout the season, while the second system is formed by all the other players. In this scenario, we evaluated the turnover from the two work systems using a $70 \%$ weight for signings $\left(\mathrm{IN}_{\mathrm{i}, 11}\right)$ during the season (i) and the trades $\left(\mathrm{OUT}_{\mathrm{i}, 11}\right)$, as compared to those of the previous season (i-1) for the 11 players in the first system, with a $30 \%$ weight assigned to signings $\left(\mathrm{IN}_{\mathrm{i}, \mathrm{all}-11}\right)$ and trades $\left(\mathrm{OUT}_{\mathrm{i}, \text { all-11 }}\right)$ during the season (i) in comparison to those of the previous season (i-1) for the players in the second system (all-11). This scenario assumes that all players are important to team performance, 
but it uses weights to differentiate between those who form the core of the team (or the central labour system) and the other players. This model is a moderate alternative to the other two. All of these considerations are shown in formula (4).

$$
\text { Turnover }_{C, i}=\frac{\left[0.7 \cdot\left(I N_{i, 11}+O U T_{i-1,11}\right)+0.3 \cdot\left(I N_{i, a l l-11}+O U T_{i-1, a l l-11}\right)\right] \cdot \frac{1}{2}}{0.7 \cdot(11)+0.3 \cdot\left(N_{i-1}-11\right)}
$$

Finally, in the last scenario, each player has a different job on the team, depending on the number of games played during the season. In this scenario, turnover is evaluated as the sum of the number of games played by signed players during season (i) plus the number of games played by traded players compared to that number for the previous season (i-1) and divided by the sum of matches played by all of the players during the season (ALL). The objective of this scenario is to consider the weight of turnover in relation to the importance of each player, based on the number of games that the player has played during the season. Formula (5) presents the turnover calculations for this scenario.

$$
\text { Turnover }_{D, i}=\frac{\Sigma\left(P_{I N, i}+P_{O U T, i-1}\right)}{\sum P_{A L L}}
$$

In calculating turnover, we also consider different ranges of seasons. The first scenario assumes that turnover among players during a season only affects the efficiency for that season. In other words, player signings and player trades are only counted for one season as compared to those of the previous season. Nevertheless, as was explained in the literature review and hypotheses sections, the members of a work group need time to unlearn or modify routines that they learned from people who have left the group, and they also need time to adapt to the new skills of the new team members. Similarly, the new group 
members require a period of adaptation and assimilation that allows them to absorb knowledge and group routines. From an empirical perspective within the world of sports, and more specifically in the world of elite football, one routinely sees great football players struggling to play their best for one or more seasons after joining a new team. Therefore, the rest of the scenarios take into account signings and trades for more than one year. For example, the second scenario considers signings and trades for the previous two seasons. Similarly, the third scenario considers signings and trades for the previous three seasons, and finally, the fourth scenario considers signings and trades for the previous four seasons. Scenarios with more than four seasons were not taken into account, as it is extremely rare to find player contracts that are longer than 4 seasons, rather they usually range from 2 to 4 seasons. These four scenarios are reflected in formulas 6, 7, 8, and 9, respectively.

$$
\begin{aligned}
& \text { Turnover }_{T 1, i}=f_{i}\left(I N_{i}, O U T_{i-1}\right) \\
& \text { Turnover }_{T 2, i}=f_{i}\left(I N_{i}, I N_{i-1}, O U T_{i-1}, O U T_{i-2}\right) \\
& \text { Turnover }_{T 3, i}=f_{i}\left(I N_{i}, I N_{i-1}, I N_{i-2}, O U T_{i-1}, O U T_{i-\mathbf{2}}, O U T_{i-3}\right) \\
& \text { Turnover }_{T 4, i}=f_{i}\left(I N_{i}, I N_{i-1}, I N_{i-2}, I N_{i-3}, O U T_{i-1}, O U T_{i-2}, O U T_{i-3}, O U T_{i-4}\right)
\end{aligned}
$$

Although the four scenarios address turnover for 1 to 4 seasons, it is also necessary to consider the possibility that signings and trades in each of the seasons do not have the same weight when calculating turnover. In other words, having hired a player three years ago may not have the same effect on group efficiency as recruiting a player with similar characteristics in the current season. For this reason, we considered it appropriate to segment each of these scenarios into three new sub-scenarios, except in the case of the first 
scenario, which only considers the current season's signings and trades in relation to those of the previous season.

For the second scenario, in which two seasons are considered in order to calculate turnover, the first sub-scenario proposes that the signings and trades during the period being analysed are assigned the same weight of 0.5 . The second sub-scenario suggests that player signings and trades during a particular season are more important than those of the previous season, which are assigned weights of 0.7 and 0.3 , respectively. Finally, the third sub-scenario proposes that the signing and trading of players in the most recent season are much more significant than those of the previous season; they are thus given weights of $17 / 20$ and $3 / 20$, respectively. These three segments are shown in formulas 10,11 , and 12 , respectively.

$$
\begin{aligned}
& \text { Turnover }_{T 2 S_{1, i}}=\frac{\mathbf{1}}{\mathbf{2}} \cdot \text { Turn }_{i}+\frac{\mathbf{1}}{\mathbf{2}} \cdot \text { Turn }_{i-1} \\
& \text { Turnover }_{T 2 S 2, i}=\frac{\mathbf{7}}{\mathbf{1 0}} \cdot \operatorname{Turn}_{i}+\frac{\mathbf{3}}{\mathbf{1 0}} \cdot \text { Turn }_{i-1} \\
& \text { Turnover }_{T 2 \mathrm{~S}_{3, i}}=\frac{17}{20} \cdot \text { Turn }_{i}+\frac{\mathbf{3}}{\mathbf{2 0}} \cdot \text { Turn }_{i-1}
\end{aligned}
$$

The third scenario is also divided into three sub-scenarios. In the first, the signing and trading of players during three seasons have the same weight as player turnover, i.e. 1/3. The second uses weights of $1 / 2,1 / 3$, and $1 / 6$, respectively, for signings and trades during the previous three seasons. Finally, the third sub-scenario gives the most weight to the signing and trading of players in the most recent season, so that the rest of the seasons have 
weights of $7 / 10,1 / 5$, and $1 / 10$, respectively. These three sub-scenarios are reflected in formulas 13,14 , and 15 , respectively.

$$
\begin{aligned}
& \text { Turnover }_{T \mathbf{3} S 1, i}=\frac{\mathbf{1}}{\mathbf{3}} \cdot \operatorname{Turn}_{i}+\frac{\mathbf{1}}{\mathbf{3}} \cdot \operatorname{Turn}_{i-\mathbf{1}}+\frac{\mathbf{1}}{\mathbf{3}} \cdot \operatorname{Turn}_{i-\mathbf{2}} \\
& \text { Turnover }_{T_{3 S 2, i}}=\frac{\mathbf{1}}{\mathbf{2}} \cdot \operatorname{Turn}_{i}+\frac{\mathbf{1}}{\mathbf{3}} \cdot \operatorname{Turn}_{i-\mathbf{1}}+\frac{\mathbf{1}}{\mathbf{6}} \cdot \operatorname{Turn}_{i-\mathbf{2}} \\
& \text { Turnover }_{\text {TaS3,i }_{i}}=\frac{\mathbf{7}}{10} \cdot \operatorname{Turn}_{i}+\frac{\mathbf{1}}{\mathbf{5}} \cdot \operatorname{Turn}_{i-\mathbf{1}}+\frac{\mathbf{1}}{\mathbf{1 0}} \cdot \operatorname{Turn}_{i-\mathbf{2}}
\end{aligned}
$$

The fourth scenario is also split into three sub-scenarios. In the first one, the weight of signings and trades is equal throughout the four seasons. The second suggests that the signings and trades during one season are more important than those of the previous season, using weights of $2 / 5,3 / 10,1 / 5$, and $1 / 10$, respectively. Finally, the third sub-scenario proposes that player signing and trading in the most recent season are much more significant than in the previous seasons, assigning weights of $3 / 5,1 / 4,1 / 10$, and $1 / 20$, respectively. These three sub-scenarios are reflected in formulas 16, 17, and 18, respectively.

$$
\begin{aligned}
& \text { Turnover }_{T \mathbf{4} 1_{1}, i}=\frac{1}{\mathbf{4}} \cdot \operatorname{Turn}_{i}+\frac{\mathbf{1}}{\mathbf{4}} \cdot \operatorname{Turn}_{i-\mathbf{1}}+\frac{\mathbf{1}}{\mathbf{4}} \cdot \operatorname{Turn}_{i-\mathbf{2}}+\frac{\mathbf{1}}{\mathbf{4}} \cdot \operatorname{Turn}_{i-\mathbf{a}} \\
& \text { Turnover }_{T S 2, i}=\frac{2}{5} \cdot \operatorname{Turn}_{i}+\frac{\mathbf{3}}{10} \cdot \operatorname{Turn}_{i-1}+\frac{1}{5} \cdot \operatorname{Turn}_{i-\mathbf{2}}+\frac{\mathbf{1}}{10} \cdot \operatorname{Turn}_{i-\mathbf{3}} \\
& \text { Turnover }_{T \mathbf{4} S, i}=\frac{\mathbf{3}}{\mathbf{5}} \cdot \operatorname{Turn}_{i}+\frac{1}{\mathbf{4}} \cdot \operatorname{Turn}_{i-1}+\frac{1}{10} \cdot \operatorname{Turn}_{i-2}+\frac{1}{20} \cdot \operatorname{Turn}_{i-3}
\end{aligned}
$$

Using the four scenarios related to work systems as the vertical axis and using the four scenarios that refer to the time considered (seasons) to calculate turnover, we obtain the 
figures in Table 1, which presents a summary of the models analysed in the study. The three sub-scenarios that are used to account for turnover from more than one season are also used in the turnover calculations. The model names employ the "Model ijk" notation, in which $i$ represents the work system, j symbolises the number of seasons considered, and $\mathrm{k}$ is the specific segment of that scenario.

\section{[INSERT TABLE 1 HERE]}

For example, the formula for model C22 (19) represents the degree of turnover where signings and trades in the first work system (which, again, contains the 11 players who have played the most matches during the season) have a weight of $70 \%$, and where the changes in the group that contains the rest of the players have a weight of $30 \%$.

Furthermore, it is assumed that the signings and trades from the most recent season have a weight of $85 \%$, whereas those of the previous season have a weight of $15 \%$.

Turnover $_{C 22, i}=+0.85\left[\frac{0.7 \cdot\left(H_{i, 11}+\text { OUT }_{i-1,11}\right)+0.3 \cdot\left(H_{i, \text { all }-11}+O U T_{i-1, a l l 11}\right)}{N_{i-1}}\right]++0.15\left[\frac{0.7 \cdot\left(H_{i-1,11}+O U T_{i-2,11}\right)+0.3 \cdot\left(H_{i-1, a l l-11}+O U T_{i-2, a l l 11}\right)}{N_{i-\mathbf{z}}}\right]$

\section{Results}

In order to test the hypotheses, we analysed 40 different models (see Table 1). As we have already described, we classified these models according to two concepts: (1) the number of seasons considered to calculate the turnover, along with their relative weight, and (2) the degree of segmentation of the work system (1, 2, or several) and its relative weight. For each model, we have performed a quadratic regression between the turnover of players and team efficiency in order to find out if any model could satisfy the first hypothesis. Among 
the 40 models tested, only three are significant: models D32, D41, and D42. These results suggest that there is an inverted U-shaped relationship between the turnover of the teams and their efficiency under some conditions (see hypotheses 2 and 3). Therefore, it is concluded that the first hypothesis was supported.

Below are the results obtained using the simplest and most basic model (model A11), which show that (1) the high and low values of all players have the same effect on the efficiency of the team and (2) only the turnover that occurred in the most recent season has an effect on team performance. This model serves as a baseline for the other models.

\section{Results of the Model A11}

Figure 2 shows the level of turnover according to the criteria for model A11, in which the horizontal axis has a normalised value between 0 and 1 , and in which the vertical axis indicates the efficiency of the football team during the season. Figure 2 shows the overall performance of the team during 21 seasons, depending on the level of turnover. We used 21 seasons instead of the initially selected 24 seasons because information from three seasons is required to calculate the turnover for certain models. At a simple glance, Figure 2 seems to show no relationship between the two model variables. Table 2 shows the results obtained by performing an F-test with a second-degree polynomial regression on the data obtained from model A11. The test results show that the average of points is better than that obtained using the polynomial regression. 


\section{[INSERT TABLE 2 HERE]}

Results of the Significant Models: C32, D41, and D42

After accepting the first hypothesis, hypotheses 2 and 3 suggest that this relationship only appears when we consider a significant period of time and several work systems with their own respective weights. Consequently, in order to test these two hypotheses, we had to check whether this relationship only appears in the models which consider 3 or 4 seasons (H2) and several work systems with different weights (H3). As previously mentioned, only three models (which are quite similar to one other) were found to be significant in this study: models D32, D41, and D42. The levels of exploration and exploitation in model D32 are evaluated based on the assumption that each group member has a significance proportional to the number of games played during the season. The model also assesses the turnover that occurred during the last three seasons, using weights of 70\% (last season), 20\% (two seasons ago), and 10\% (three seasons ago). Model D41 also assumes that all team members have an importance proportional to the number of games that they played in the last season. It also assesses the turnover that occurred during the last four seasons using weights of 50\% (last season), 25\% (two seasons ago), 15\% (three seasons ago), and 10\% (four seasons ago). Finally, the level assessment of exploration and exploitation in model B also suggests that all team members have an importance that is proportional to the number of games that they played during the last season. It also assesses the turnover that has occurred during the last four seasons using weights of 60\% (last season), 25\% (two seasons ago), 10\% (three seasons ago), and 5\% (four seasons ago). 
Like Figure 2, Figure 3 shows the football team's performance during 21 seasons, according to the level of turnover in each of the three models. In addition, we have included the quadratic regression function that best fits the set of points associated with each model. It should be noted that this function tends toward an inverted $\mathrm{U}$ shape, as proposed in hypothesis H1. Meanwhile, Table 3 shows the results of an F-test conducted with a seconddegree polynomial regression on data obtained from each of the three models: D32, D41, and D42. The test results show that the results of the polynomial regression are better than the average of the points in the case of the A11 model and the other models that were initially considered. Table 3 also shows the most significant results of the quadratic regression for each of the models and their coefficients of determination (R2), whose value is always greater than 0.6. The large coefficients of the Table 3 are due to the fact that the regressions have been carried out without centring the scores. Therefore, we argue for the existence of an inverted U-shaped relationship between turnover and team efficiency if certain criteria are met in the evaluation of changes on a football team.

\section{[INSERT FIGURE 3 HERE]}

\section{[INSERT TABLE 3 HERE]}

\section{Discussion and Conclusions}

The objective of this research was to determine whether the theories regarding the equilibrium between levels of exploration and resource exploitation (March, 1991) could be applied at the micro level and, more specifically, to a high-performance team. These theories tend to suggest the existence of an inverted U-shaped relationship between an organisation's levels of exploration and exploitation of resources and the efficiency of that 
organisation. However, these theories are applied mainly to large organisations and tend to be difficult to generalise to lower, more specific levels, such as the individual or group level (e.g. Gupta, Smith and Shalley, 2006). To test whether such generalisation was possible, we used 24 seasons of historical data from one of the most popular football clubs in the world, which has approximately 22 players. The results supported this hypothesis.

This study presented three hypotheses. The first one (H1) proposed the existence of an inverted U-shaped relationship between the level of turnover among the members of a high performance team and its efficiency, whereas the second and third hypotheses (H2 and H3) provided more details regarding the nature of this relationship. The results of some models (D32, D41, and D42) satisfy the first hypothesis. Moreover, the characteristics of these models suggest some interesting issues related to the last two hypotheses. These models consider a significant period of time (in 1 model 3 seasons are considered, and in 2 models 4 seasons are considered) in the process used to evaluate the turnover according to the method proposed by hypothesis 2. We can highlight one model (D41) that considers equal weights for each season, and two models (models D32 and D42) that consider a slight decrease in weight for each previous season. There is support for the latter approach. Note that models D33 and D43 are not significant, because the weights for the different seasons are too different; the results are similar to those of the models that only consider seasons 1 and 2.

Hypothesis 3 proposed that the relationship between turnover and efficiency also depends on the number or the segmentation of the work systems and their weights. Again, the results satisfy this hypothesis, because the three models (D32, D41, and D42) are characterised by a segmentation with more than 2 groups in which each player has his own 
weight. One of the three featured models, model D41, provides the best results, yielding an R2 higher than 0.7 and a p-value for the variable turnover squared that is smaller than 0.01 . The main difference between this model and the other two models is that the weights of the high- and low-level players in the last four seasons are the same.

The implications of these results regarding efficiency and turnover among the members of a high-performance team are important for researchers and practitioners. First, the results show that theories based on the exploration and exploitation of resources can also be applied to small teams (or at least high-performance teams, such as professional sports teams). These results could facilitate a wealth of new research and suggest that it is important to balance the exploration and exploitation of human resources in small groups, such as high-performance teams. Moreover, managers and executives on high-performance sports teams can confirm that signing and trading players plays a much greater role in the results over the medium and long term than in the short term. Thus, it is important to pursue a player turnover strategy that involves a minimum period of 3 or 4 seasons to attempt to maximise team efficiency. We do not wish to imply that the main determinant of the efficiency of a high-performance team is turnover among its members; however, turnover is one of many influential factors, and the managers of these teams should be aware of the effects of turnover if they hope to maximise efficiency in the medium and long term.

These results also suggest other interesting implications. On the one hand, a few years ago some European teams started to apply aggressive financial policies to sign players due to their purchase by important businessmen and millionaires. These policies, which were oriented towards short-term objectives, have been predominantly negative. One possible 
explanation of these results is the lack of consideration of the effects that turnover has in a period of 3 or 4 seasons (taking into account the results of this research). Although the policies governing European football, such as the ranking and seeding system used by UEFA in the Champions League, tend to reinforce the status quo (Plumley and Flint, 2015), certain new policies, such as financial fair play, can help managers of sports teams to consider their strategies over longer periods (3 and 4 seasons), rather than just in the short term. On the other hand, the results also show some interesting implications regarding human capital policies on sport teams. This research has considered different scenarios, where the weight of the players has been quantified in different ways. The results show that all players are important in achieving team goals, with different weights depending on their status and participation in the matches. More specifically, and unlike what happens in other sectors, the segmentation of players into two large work systems is not enough to manage the human capital of a sport team. Therefore, the specific human capital policies on sport teams should be different from the standards we can find in most companies or teams.

Although the results statistically suggest the existence of an inverted U-shaped relationship between turnover levels and the efficiency of labour teams, our figures show that we have obtained information primarily from the central part of the data (the equilibrium point) and that the same is true for the exploration levels. Further research can assess whether this result is a consequence of the case chosen for the study or is due to other reasons related to March's (1991) argument. The main limitation of this study, which is common to most published research in this area, is the presence of "unobservable" elements, such as the skill of the coach and team manager (Gerrard, 2005), which could moderate the actual relationship between turnover among the team members and their results at the end of the 
season. Other examples might include environmental conditions, including the type of members and spectators, the press coverage that the club receives, and the relationship between managers and fans.

Although this research has allowed us to obtain information about the relationship between the turnover and the efficiency of sport teams and to apply an analytical extrapolation in order to explain what happens in this situation, the selection of just one case is not enough to extrapolate the results directly to the rest of teams. Taking into account that the goals of high- and low-achieving teams are not the same, and that some high-achieving teams may also have other additional goals, we have to employ a greater degree of caution in drawing our conclusions. For this reason, the study of different types of football teams according to their specific goals and the results of our research could help to define non-observable aspects in the relationship that we have studied.

Gupta, Smith and Shalley (2006) suggest that there is a conflict between continuity and orthogonality in the processes of resource exploration and exploitation. This research has established that the levels of exploration and exploitation of the members of highperformance teams function as two end points on the same continuum. However, some researchers suggest that both elements could be orthogonal, and consequently, we might encounter high levels of exploration along with high levels of exploitation and vice versa. If we bear this caveat in mind, it seems that the unique representation of the equilibrium point and the exploration section might be explained by the turnover variable, and that it would be necessary to identify a new variable to assess the levels of exploitation. This opens up 
interesting possibilities for future research on the balance between the processes of resource exploration and exploitation on teams.

\section{References}

Abelson, M., and Baysinger, B. (1984),“Optimal and dysfunctional turnover: Towards an organizational level model”,Academy of Management Review, Vol. 9, pp. 331341.doi:10.5465/amr.1984.4277675

Arthur, J. B. (1994),“Effects of human resource systems on manufacturing performance and turnover”, Academy of Management Journal, Vol. 37, pp. 670-687. $\underline{\text { doi:10.2307/256705 }}$

Bamberger, P., and Meshoulam, I. (2000),Human Resource Strategy, Thousand Oaks, CA: Sage Publications, Inc.

Cascio, W. (1998),Managing human resources: Productivity, quality of work life, profits, Boston: Irwin McGraw-Hill.

Clopton, A.W. (2011), Social capital and team performance, Team Performance Management, Vol. 17 No. 7, pp. 369-381. doi:10.1108/13527591111182634

Datta, D., Guthrie, J., and Wright, P. (2005), Human resource management and productivity: Does industry matter?,Academy of Management Journal, Vol. 48, pp. 135- 145. doi:10.5465/AMJ.2005.15993158

Dechant, K., Marsick, V., and Kasl, E. (2000), Team learning: A model for effectiveness in high performing teams. In M. M. Beyerlein, D. A. Johnson, and S. T. Beyerlein (Eds.), Team development (pp. 1-21). New York: JAI, Elsevier.

Dess, G. D., and Shaw, J. D. (2001), Voluntary turnover, social capital, and organizational performance,Academy of Management Review, Vol. 26 No. 3, pp. 446-56. doi:10.5465/amr.2001.4845830 
Dohrn, S., Lopez, Y. S. (2015), Leadership succession and performance: An application to college football. Journal of Sport Management, Vol. 29, no. 1, pp. 7692.doi:10.1123/jsm.2013-0211

Economist (2007), Accounting for good people. July 21: 73-75.

Edmondson, A. (1999), Psychological safety and learning behaviour in work teams. Administrative Science Quarterly, Vol. 44, pp. 350-383. doi:10.2307/2666999

Espitia-Escuer, M.,\& García-Cebrián, L. I. (2006), Performance in sports teams: results and potential in the professional soccer league in Spain. Management Decision, Vol. 44, No. 8, pp. 1020-1030.doi:10.1108/00251740610690595

Foster, W.M. and Washington, M. (2009), Organizational structure and home team performance, Team Performance Management, Vol. 15 No. 3-4, pp. 158-171. doi:10.1108/13527590910964937

Gerrard, B. (2005), A resource-utilization model of organizational efficiency in professional sports teams, Journal of Sport Management, Vol. 19, pp. 143-169.

Glebbeek, A. and Bax, E. (2004), Is high employee turnover really harmful? An empirical test using company records,Academy of Management Journal, Vol. 47 No. 2, pp. 277-286. doi:10.2307/20159578

Gupta, A. K., Smith, K. G. and Shalley, C. E. (2006), The interplay between exploration and exploitation,Academy of Management Journal, Vol. 49 No. 4, pp. 693-706. doi:10.5465/AMJ.2006.22083026

Guthrie, J. P. (2001), High-involvement work practices, turnover, and productivity: Evidence from New Zealand,Academy of Management Journal, Vol. 44, pp. 180190. $\underline{\text { doi: } 10.2307 / 3069345}$ 
Harrison, D., Virick, M. and William, S. (1996), Working without a net: Time, performance, and turnover under maximally contingent rewards,Journal of Applied Psychology, Vol. 81, pp. 331-345. doi:10.1037/0021-9010.81.4.331

Harris, M., Tang, K.K. and Tseng, Y.P. (2006), Employee turnover: Less is not necessarily more? In B. H. Baltagi (Ed.), Panel data econometrics: Theoretical contributions and empirical applications (Contributions to economic analysis, vol. 274). pp. 327-350. Amsterdam: Elsevier Science.

Kacmar, M., Andrews, M., Van Rooy, D., Steilberg, C. and Cerrone, S. (2006), Sure everyone can be replaced...but at what cost? Turnover as a predictor of unit-level performance,Academy of Management Journal, Vol. 49, pp. 133-144.

\section{doi:10.5465/AMJ.2006.20785670}

Katzenbach, J. R. and Smith, D. K. (1999),The wisdom of teams: Creating the high performance organization, New York: Harper-Perennial.

Lepak, D. P. and Snell, S. A. (1999), The Human Resource Architecture: Toward a theory of human capital allocation and development,Academy of Management Review, Vol. 24 No. 1, pp. 31-48. doi:10.2307/259035

Lepak, D., Taylor, M., Tekleab, A., Marrone, J. and Cohen, D. (2007), An examination of the use of high-investment human resource systems for core and support employees,Human Resource Management, Vol. 48, pp. 223-246. doi:10.1002/hrm.20158

Lunnan, R. and Barth, T. (2003), Managing the exploration vs. exploitation dilemma in transnational "bridging teams”, Journal of World Business, Vol. 38 No. 2, pp. 110126. doi:10.1016/S1090-9516(03)00005-1 
March, J. G. (1991), Exploration and exploitation in organization learning,Organization Science, Vol. 2, pp. 71-87. doi:10.1287/orsc.2.1.71

Mobley, W. H. (1982),Employee turnover, causes, consequences, and control, Reading, MA: Addison-Wesley.

Mohrman, S. A., Cohen, S. G. and Mohrman, A. M. J. (1995),Designing team-based organizations, San Francisco: Jossey-Bass.

Morrow, P. and McElroy, J. (2007), Efficiency as a mediator in turnover-organizational performance,Human Relations, Vol. 60, pp. 827-849.

\section{doi:10.1177/0018726707080078}

Nissen, R. (2014), Playing the game: How football directors make sense of dismissing the coach. International Journal of Sport Management and Marketing, Vol. 15, no. 34, pp. 214-231. doi:10.1504/ijsmm.2014.072009

Plumley, D., \& Flint, S. W. (2015), The UEFA Champions League: maintaining the status quo? Team Performance Management, Vol. 21, No. 5/6, pp. 247-258. doi:10.1108/TPM-01-2015-0003

Shaw, J. D., Delery, J. E., Jenkins, G. D. and Gupta, N. (1998), An organization-level analysis of voluntary and in-voluntary turnover,Academy of Management Journal, Vol. 41, pp. 511-525. doi:10.2307/256939

Shaw, J. D., Duffy, M. K., Johnson, J. J. and Lockhart, D. (2005), Turnover, social capital losses, and performance,Academy of Management Journal, Vol. 48 No. 4, pp. 594606. doi:10.5465/AMJ.2005.17843940

Shaw, J. D., Gupta, N. and Delery, J. E. (2005), Alternative conceptualizations of the relationship between voluntary turnover and organizational performance,Academy 
of Management Journal, Vol. 48 No. 1, pp. 50-68.

doi:10.5465/AMJ.2005.15993112

Siebert, W. S. and Zubanov, N. (2009), Searching for the optimal level of employee turnover: A study of a large U.K. retail organization,Academy of Management Journal, Vol. 52 No. 2, pp. 294-313. doi:10.5465/AMJ.2009.37308149

Ter Weel, B. (2011), Does Manager Turnover Improve Firm Performance? Evidence from Dutch Soccer, 1986-2004. De Economist, Vol.159, No. 3, pp. 279-303. doi:10.1007/s10645-010-9157-y

Trequattrini, R., Lombardi, R. and Battista, M. (2015),Network analysis and football team performance: a first application, Team Performance Management, Vol. 21 No. 1-2, pp. 85-110. doi:10.1108/TPM-03-2014-0016

Ton, Z. and Huckman, R. S. (2008),Managing the impact of employee turnover on performance: The role of process conformance,Organization Science, Vol. 19 No. 1, pp. 56-68. doi:10.1287/orsc.1070.0294

Wells, J.E. and Peachey, J.W. (2011), Turnover intentions: Do leadership behaviors and satisfaction with the leader matter?,Team Performance Management, Vol. 17 No. 1, pp. 23-40. doi:10.1108/13527591111114693 